\title{
PARTITIONAL RESPIROMETRY IN CARDIO-PULMONARY DISEASE
}

\author{
BY \\ ROY J. SHEPHARD \\ From the Department of Preventive Medicine and Industrial Health, University College of \\ Medicine, University of Cincinnati, Cincinnati, Ohio, U.S.A.*
}

(ReCEIVEd For PUblication aUgust 5, 1958)

Respiratory disorders can now be classified by the average laboratory as primary defects of respiratory mechanics or of gas uptake, and the verdict is accepted with reasonable confidence. However, further classification of disordered gas uptake is still a tedious and uncertain business. The aim of partitional respirometry is to meet this challenge, distinguishing three basic components of the gas uptake process (effective dead space, diffusing capacity, and pulmonary perfusion). Inconvenience to the patient is minimal, since all that is required is the breathing of a composite gas mixture containing very low concentrations (300 p.p.m.) of ether, carbon monoxide, and acetylene. The uptake of each gas is determined by infra-red analysis. Ether uptake is dependent mainly on ventilation and slightly on perfusion, carbon monoxide uptake on ventilation and diffusion, and acetylene uptake on perfusion and ventilation. A series of simultaneous equations with terms in ventilation, diffusion, and perfusion are obtained, and it is then a simple matter to partition the gas uptake process into these three independent components.

The technique was originally introduced by Hatch and Cook (1955), and some data relating to mine-workers were briefly reported at that time. More recently, simultaneous analysis of the three gases and other refinements have considerably increased the precision of the method, and multiple regression analyses which permit the prediction of normal values have been completed (Shephard, 1958). The main object of the present paper is to evaluate the usefulness of partitional respirometry in a variety of patients studied in some detail by conventional clinical and physiological methods.

*Present address: Ministry of Supply, C.D.E.E., Porton Down, Salisbury, Wilts, England.

\section{MeTHODS}

Partitional Respirometry.-The technique is essentially unchanged from that used in a previous study (Shephard, 1958). The subject breathed the test mixture containing $0.03 \%$ each of ether, carbon monoxide, and acetylene from a Douglas bag, and exhaled into a 1 litre mixing chamber fitted with a small fan. Mixed gas was pumped continuously at a rate of $1 \mathrm{l} . / \mathrm{min}$. from this chamber through a chain of three infra-red gas analysers, and back to the main expiratory hosepipe for volume measurement.

The infra-red gas analysers were the basic Mine Safety Appliance Company design but fitted by the manufacturers with appropriate comparison and filter cells for the analysis of ether, carbon monoxide, and acetylene respectively. A continuous record of gas concentrations was obtained by feeding the electrical output of the analysers to a Bristol three-channel recorder. Knowing the inspired concentrations from previous analysis, it was then a simple matter to calculate fractional uptake of the three gases. Technical problems are related mainly to the handling of water vapour, which has a large effect on the reading of the acetylene analyser. In the present instance the gas mixture was saturated with water vapour by passing through a small bubbler unit before entering the acetylene and carbon monoxide analysers. However, owing to the high solubility of ether in water, it was necessary to analyse this gas at expired humidity.

The respiratory pattern during the test was measured by a differential spirometer system with a very low resistance to gas flow. A pump was attached to the oxygen supply tube of a 7-litre spirometer, and air drawn out of the bell at a preselected rate, usually $61 . / \mathrm{min}$. The slope of the tracing then indicated the difference between the patient's minute volume and the preselected rate of pumping, while oscillations of the tracing indicated the respiratory rate, and approximately half the tidal volume of individual breaths.

Subsequent analysis of data proceeds from the assumption that in a homogeneously ventilated and 
perfused system, uptake of foreign gas encounters three resistances arranged in series-ventilatory (proportional to the reciprocal of alveolar ventilation $\dot{\mathrm{V}}_{\mathrm{A}}$ ), diffusional (proportional to the reciprocal of diffusing capacity $\dot{\mathrm{D}}$ ), and circulatory (proportional to reciprocal of blood flow $\dot{Q}$ multiplied by the air/ liquid partition coefficient $\lambda$ for the gas). Overall conductance of the gas $\dot{U}$ is then given by

$$
\frac{1}{\dot{U}}=\frac{1}{\dot{\mathrm{V}}_{\mathrm{A}}}+\frac{1}{\dot{\mathrm{D}}}+\frac{1}{\lambda \dot{\mathrm{Q}}}
$$

For carbon monoxide, ${ }^{1} / \dot{\lambda} \dot{Q}$ is negligible. For acetylene and ether, ${ }^{1} / \dot{D}$ is insignificant, and taking real values of $\lambda=0.75$ (acetylene) and $\lambda=15$ (ether), the expression simplifies to

$$
\begin{gathered}
\frac{1}{\dot{\mathrm{U}}_{\mathrm{AC}}}=\frac{1}{\dot{\mathrm{V}}_{\mathrm{A}}}+\frac{1}{0.75 \dot{\mathrm{Q}}} \\
\frac{1}{\dot{\mathrm{U}}_{\mathrm{E}}}=\frac{1}{\dot{\mathrm{V}}_{\mathrm{A}}}+\frac{1}{15 \dot{\mathrm{Q}}}
\end{gathered}
$$

It can be seen that ether uptake depends mainly on ventilation, and acetylene uptake on blood flow and ventilation. Further, if the fractional uptake of each gas is known, the simultaneous equations given above permit estimation of alveolar ventilation and blood flow. In a non-homogeneous system, as in disease states, values are smaller and reflect the effective alveolar ventilation, effective diffusing capacity, and effective blood flow that would achieve a similar gas uptake in a homogeneous system.

All of the patients found the investigation more pleasant than most respiratory tests. They were given a 15-minute preliminary rest period, and during the last five minutes were connected to the breathing circuit. They were warned that they might detect a very slight sweet odour, and in most cases there was little or no disturbance of the respiratory rhythm when the foreign gas mixture was introduced.

The nitrogen meter dead space, corresponding approximately with the anatomical dead space, was measured by servo-spirometer, nitrogen meter, and data linearizer, as described previously (Shephard, 1956a, 1958). Volumes were adjusted to a standard critical expiratory phase of 2.5 seconds. The difference between nitrogen-meter and effective dead space is then a measure of the inefficiency of ventilation at the alveolar level.

Other Physiological Techniques.-Maximum breathing capacity was determined by a lowresistance, open-circuit system, using a Douglas bag, mask, and valve-box with 3 -in. diameter ports. The importance of respiratory rate as a determinant of breathing capacity has been emphasized in several recent studies (Shephard, 1957; Bartlett, Brubach, and Specht, 1958), and accordingly subjects repeated the test at increasing rates until a maximum capacity was attained.
Total vital capacity and forced expiratory volume were determined by a modern low-resistance spirometer with light-weight bell. This arrangement gives a dynamic error of not more than $1 \%$ in the measurement of one-second volume (Shephard, 1956b).

Functional residual capacity and helium-mixing curves were obtained by a closed-circuit apparatus with automatic volume stabilization (Godart " pulmotest"). A secondary record of oxygen " consumption" served as a check that functional residual capacity did not alter during the test. Mixing efficiency was expressed in terms of the empirical index $\mathrm{I}_{0}$ (Bates and Christie, 1950).

Cardiac catheterization was carried out in some cases, using a standard technique with an image intensifier permitting continuous observation of the catheter tip. Arterial oxygen content and capacity and carbon dioxide content were determined by Van-Slyke analysis, samples being collected before and after a standard exercise test (climbing a 10-in. step 15 times per min. for two min.).

\section{RESUlts}

Subjects with a variety of conditions (congenital heart disease, emphysema, bronchitis and bronchiectasis, pneumoconiosis, alveolar-capillary block, and old age) have been studied by the partitional respirometry technique. To avoid repetition, all results are summarized in Table $I$. Values prefixed by a $P$ are predicted from the multiple regression equations for normal subjects.

(1) Congenital Heart Disease.-Two patients with left-to-right intracardiac shunts were seen. One was a young adult, apparently in good health ; the other was older, and showed signs of shunt reversal and cardiac failure.

Uncomplicated Left-to-right Shunt. - A nurse, C. R., aged 20, apparently in good health, was admitted to hospital with a provisional diagnosis of atrial septal defect. Physical examination showed no significant abnormality apart from a moderate systolic murmur to the left of the sternum, maximal in the third and fourth interspaces. The pulmonary flow at cardiac catheterization was $13.21 . / \mathrm{min}$. $\left(8.151 . / \mathrm{m}^{2} / \mathrm{min}\right.$.), and the systemic flow $3.51 . / \mathrm{min}$., indicating a left-to-right shunt of $9.71 . / \mathrm{min}$. Individual blood samples showed the increase in oxygen saturation to occur largely at the atrial level, and the presence of an ostium primum defect was subsequently confirmed by operation. The pulmonary arterial pressure $(25 / 8 \mathrm{~mm}$. $\mathrm{Hg}$ ) was unusually low, considering her age and the size of the shunt (Shephard, 1954). Arterial puncture showed a normal resting oxygen saturation $(98.8 \%)$.

The effective pulmonary flow, as determined by partitional respirometry, corresponded very closely with the previous Fick measurement, and the 
TABLE I

PARTITIONAL RESPIROMETRY DATA IN 14 SUBJECTS

\begin{tabular}{|c|c|c|c|c|c|c|c|c|c|c|}
\hline Subject & $\begin{array}{c}\text { Age } \\
\text { (Yr.) }\end{array}$ & Sex & $\begin{array}{l}\text { Body } \\
\text { Surface } \\
\text { Area } \\
\left(\mathrm{m} .^{2}\right)\end{array}$ & $\begin{array}{l}\text { Respiratory } \\
\text { Minute } \\
\text { Volume } \\
\text { (1./m. } / \mathrm{min} .)\end{array}$ & $\begin{array}{c}\text { Tidal } \\
\text { Volume } \\
\text { (ml. B.T.P.S.) }\end{array}$ & $\begin{array}{l}\text { Respi- } \\
\text { ratory } \\
\text { Rate } \\
\text { (per } \\
\text { min.) }\end{array}$ & $\begin{array}{c}\text { Effective } \\
\text { Dead Space } \\
\text { (ml. B.T.P.S.) }\end{array}$ & $\begin{array}{c}\mathbf{N}_{2} \text { Meter } \\
\text { Dead Space } \\
(\mathrm{ml} \text {. B.T.P.S. })\end{array}$ & $\begin{array}{l}\text { Diffusing } \\
\text { Capacity } \\
\text { (ml. mm. } \\
\text { Hg min.) }\end{array}$ & $\begin{array}{c}\text { Effective } \\
\text { Pulmonary } \\
\text { Blood Flow } \\
\left.\text { (l. } \text { m. }^{2} / \mathrm{min} .\right)\end{array}$ \\
\hline \multicolumn{11}{|c|}{ (1) Congenital Heart Disease } \\
\hline $\begin{array}{l}\text { C.R. } \\
\text { M.M. }\end{array}$ & $\begin{array}{l}22 \\
43\end{array}$ & $\begin{array}{l}\mathbf{F} \\
\mathbf{F}\end{array}$ & $\begin{array}{l}1.62 \\
1.60\end{array}$ & $\begin{array}{l}4 \cdot 67 \\
5 \cdot 31\end{array}$ & $\begin{array}{l}671 \\
369\end{array}$ & 23 & $\begin{array}{c}173(P=180)^{*} \\
80(P=142)\end{array}$ & $\begin{array}{r}87 \\
102\end{array}$ & $\begin{array}{l}61 \cdot 3(P=43 \cdot 4) \\
18 \cdot 8(P=25 \cdot 6)\end{array}$ & $\begin{array}{l}8 \cdot 12(P=5 \cdot 12) \\
7 \cdot 43(P=4 \cdot 28)\end{array}$ \\
\hline \multicolumn{11}{|c|}{ (2) Emphysema } \\
\hline $\begin{array}{l}\text { C.C. } \\
\text { O.S. } \\
\text { G.K. } \\
\text { O.N. }\end{array}$ & $\begin{array}{l}77 \\
69 \\
68 \\
83\end{array}$ & $\begin{array}{l}\mathbf{M} \\
\mathbf{M} \\
\mathbf{M} \\
\mathbf{F}\end{array}$ & $\begin{array}{l}1.75 \\
1.69 \\
1.66 \\
1.28\end{array}$ & $\begin{array}{l}5 \cdot 41 \\
7 \cdot 81 \\
6 \cdot 31 \\
4 \cdot 03\end{array}$ & $\begin{array}{r}1,064 \\
1,654 \\
581 \\
253\end{array}$ & $\begin{array}{l}9 \\
8 \\
18 \\
20 \cdot 3\end{array}$ & $\begin{array}{l}398(P=320) \\
503(P=407) \\
300(P=242) \\
115(P=126)\end{array}$ & $\begin{array}{l}115 \\
107 \\
156 \\
-\end{array}$ & $\begin{array}{r}19.4(\mathrm{P}=35.7) \\
21.8(\mathrm{P}=48.2) \\
15.1(\mathrm{P}=23.4) \\
7.5(\mathrm{P}=16.9)\end{array}$ & $\begin{array}{l}5 \cdot 16(P=4.61) \\
5.08(P=-t) \\
5.42(P=4.75) \\
2.16(P=5.91)\end{array}$ \\
\hline \multicolumn{11}{|c|}{ (3) Industrial Diseases } \\
\hline $\begin{array}{l}\text { J.E. } \\
\text { C.J. } \\
\text { E.W. }\end{array}$ & $\begin{array}{l}49 \\
49 \\
54\end{array}$ & $\begin{array}{l}\mathbf{M} \\
\mathbf{M} \\
\mathbf{M}\end{array}$ & $\begin{array}{l}1.88 \\
1.95 \\
1 \cdot 78\end{array}$ & $\begin{array}{l}6 \cdot 33 \\
5 \cdot 72 \\
7 \cdot 18\end{array}$ & $\begin{array}{l}910 \\
551 \\
670\end{array}$ & $\begin{array}{l}13 \\
20 \cdot 3 \\
19\end{array}$ & $\begin{array}{l}449(P=274) \\
266(P=247) \\
336(P=248)\end{array}$ & $\begin{array}{l}166 \\
166 \\
277\end{array}$ & $\begin{array}{r}57 \cdot 3(P=29 \cdot 4) \\
37 \cdot 2(P=35 \cdot 7) \\
8 \cdot 2(P=31 \cdot 1)\end{array}$ & $\begin{array}{l}2.90(P=3.73) \\
8 \cdot 13(P=4.73) \\
8 \cdot 12(P=3.97)\end{array}$ \\
\hline \multicolumn{11}{|c|}{ (4) Old Age } \\
\hline $\begin{array}{l}\text { L.B. } \\
\text { A.K. } \\
\text { R.M. } \\
\text { E.L. } \\
\text { F.A. } \\
\text { G.B. }\end{array}$ & $\begin{array}{l}63 \\
63 \\
62 \\
60 \\
66 \\
70\end{array}$ & $\begin{array}{l}\mathbf{M} \\
\mathbf{M} \\
\mathbf{M} \\
\mathbf{M} \\
\mathbf{M} \\
\mathbf{F}\end{array}$ & $\begin{array}{l}1.82 \\
1.85 \\
1.93 \\
1.97 \\
1.74 \\
1.57\end{array}$ & $\begin{array}{l}4 \cdot 14 \\
5 \cdot 21 \\
4 \cdot 02 \\
4 \cdot 91 \\
3 \cdot 47 \\
9 \cdot 13\end{array}$ & $\begin{array}{r}559 \\
494 \\
801 \\
586 \\
1,052 \\
898\end{array}$ & $\begin{array}{c}13 \cdot 5 \\
19 \cdot 5 \\
9 \cdot 7 \\
16 \cdot 5 \\
6 \cdot 3 \\
16\end{array}$ & $\begin{array}{l}252(P=220) \\
245(P=136) \\
311(P=291) \\
234(P=226) \\
312(P=269) \\
393(P=280)\end{array}$ & $\begin{array}{l}175 \\
163 \\
218 \\
186 \\
233 \\
162\end{array}$ & $\begin{array}{l}37 \cdot 4(P=30 \cdot 1) \\
33 \cdot 3(P=27 \cdot 1) \\
33 \cdot 3(P=35 \cdot 1) \\
45 \cdot 1(P=29 \cdot 1) \\
14 \cdot 1(P=25 \cdot 1) \\
14 \cdot 3(P=25 \cdot 3)\end{array}$ & $\begin{array}{l}6.39(P=5.53) \\
4.41(P=5.17) \\
7.09(P=5.61) \\
5.42(P=5.03) \\
3.47(P=6.52) \\
5.33(P=1.52)\end{array}$ \\
\hline
\end{tabular}

* Predicted values are given in brackets. † Tidal volume too large for use of prediction formula.

effective diffusing capacity exceeded the predicted resting value. Other findings were essentially normal.

Left-to-right Shunt with Reversal of Flow.-A woman, M. M., aged 43, was known to have had a cardiac murmur from childhood, but had completed six uneventful pregnancies, and had experienced no serious symptoms until a year previously. Three months before admission, increasing exertional dyspnoea and cyanosis had culminated in frank cardiac failure. This had improved with "digoxin" therapy, and when seen she could walk 200 yards or climb 15 stairs before resting. Clinical examination showed slight cyanosis at rest, but no finger clubbing. The cardiac apex was 1 in. to the left of the midclavicular line in the sixth interspace, and auscultation revealed a low-pitched left parasternal systolic murmur and an accentuated moderately split pulmonary second sound. A firm liver margin was palpable at least 1 in. below the costal margin, but both lung bases were clear, and there were no immediate signs of cardiac failure. At cardiac catheterization, an atrial septal defect was disclosed. The shunt appeared to be bidirectional, and as the pulmonary veins were not intubated it was necessary to assume a figure for pulmonary capillary oxygen saturation. Following the practice of Cincinnati General Hospital, a figure of $95 \%$ was adopted, indicating a pulmonary flow of $8.971 . / \mathrm{min}$., with a right-to-left shunt of $0.83 \mathrm{l} . / \mathrm{min}$. and a left-to-right shunt of $6.641 . / \mathrm{min}$. Pressure measurements showed an increased pulmonary vascular resistance and pulmonary hypertension (pressure $=90 / 40 \mathrm{~mm}$. $\mathrm{Hg}$ ). Arterial puncture showed considerable unsaturation $(86 \%)$ even at rest.

The respiratory pattern of moderate hyperventilation with rapid respiratory rate and reduced tidal volume (Table I) is typical of a left-to-right shunt with pulmonary vascular congestion (Shephard, 1955). The effective pulmonary flow as indicated by partitional respirometry exceeded the Fick value, but this discrepancy can be resolved by assuming that the pulmonary capillary blood did not achieve a saturation of more than $92 \%$. This is by no means an improbable figure in older patients with left-toright shunts (Shephard, 1954), and indeed is suggested here by the reduction in diffusing capacity. The effective dead space was less than the predicted value, probably because the prediction formulae are not fully applicable to the gas flow patterns associated with reduced tidal volumes.

(2) EMPHYSEMA.-Four elderly patients were studied. In three (C. C., O. S., and G. K.), there was evidence of asthma in addition to emphysema. These showed an increased resting ventilation. The fourth patient (O. N.), who was nearly 84 , was weaker physically and seemed unable to maintain more than a normal resting ventilation. This may represent an important transition point in the natural history of emphysema, and presents a rather different picture at partitional respirometry.

Subject C. C. was a man of 77 who had "always" suffered from periodic attacks of bronchitis, but had become increasingly short of breath in the past few years. When seen, he could walk several miles or climb several flights of stairs at his own speed. Physical and radiographic examination showed the typical features of chronic emphysema, and patchy calcification of the aorta. The diagnosis was confirmed by routine physiological procedures (Table II). 
TABLE II

ROUTINE TESTS OF PULMONARY FUNCTION IN FOUR CASES OF EMPHYSEMA

\begin{tabular}{|c|c|c|c|c|}
\hline Subject: & C.C. & O.S. & G.K. & O.N. \\
\hline \multicolumn{5}{|l|}{ Mechanics of Respiration } \\
\hline $\begin{array}{l}\text { Total vital capacity } \\
\text { B.T.P.S.) } \\
\text { One }\end{array}$ & $2 \cdot 8$ & 3.9 & $2 \cdot 8$ & $1 \cdot 3$ \\
\hline $\begin{array}{l}\text { B.T.P.S.) } \\
\text { One sec./total (\%) } \\
\text { Max. insp. pressure (mm. Hg) }\end{array}$ & $\begin{array}{l}1 \cdot 4 \\
50 \\
21\end{array}$ & $\begin{array}{ll}2 \cdot 0 \\
51 \\
31\end{array}$ & $\begin{array}{l}1 \cdot 3 \\
46 \\
20\end{array}$ & $\begin{array}{c}0 \cdot 6 \\
46 \\
8\end{array}$ \\
\hline ," exp. , , , , & 50 & 53 & & \\
\hline $\begin{array}{l}\text { Residual Volume, Gas Mixing } \\
\text { Residual volume (1. B.T.P.S.) } \\
\text { Expiratory reserve(1. B.T.P.S.) }\end{array}$ & $\begin{array}{l}3.47 \\
0.84\end{array}$ & $\begin{array}{l}5 \cdot 45 \\
0.96\end{array}$ & $\begin{array}{l}3 \cdot 15 \\
1 \cdot 48\end{array}$ & $\begin{array}{l}1 \cdot 56 \\
0 \cdot 13\end{array}$ \\
\hline $\begin{array}{l}\text { Functional residual vol. (1. } \\
\text { B.T.P.S.) }\end{array}$ & $4 \cdot 31$ & $6 \cdot 41$ & $4 \cdot 63$ & 1.69 \\
\hline $\begin{array}{l}\text { B.T.P.S.) } \\
\text { R.V./T.L.C. }(\%) \\
\text { Helium mixing index } I_{0}(\%)\end{array}$ & $\begin{array}{l}6 \cdot 07 \\
57 \cdot 3 \\
30 \cdot 0\end{array}$ & $\begin{array}{l}9 \cdot 30 \\
58 \cdot 7 \\
23 \cdot 7\end{array}$ & $\begin{array}{l}5 \cdot 99 \\
52 \cdot 4 \\
22 \cdot 7\end{array}$ & $\begin{array}{l}2 \cdot 51 \\
62 \cdot 1 \\
12 \cdot 4\end{array}$ \\
\hline
\end{tabular}

Subject O.S. was aged 69, and had experienced attacks of asthma for 23 years, and recently had been increasingly short of breath between attacks. He also had a chronic cough, producing half a cup of yellowish sputum per day, and preferred to sleep on three pillows. When seen, he could walk three miles at his own speed or climb one flight of stairs. Physical and radiographic signs of emphysema were present, with bilateral inguinal herniae and expiratory rhonchi. A firm liver margin was also palpable $1 \mathrm{in}$. below the costal margin, and there was slight ankle oedema. The aortic shadow was tortuous and broadened. Physiological tests (Table II) confirmed the primary diagnosis.

Subject G. K. was a man of 68 who had suffered from "asthma" and increasing shortness of breath since exposure to gas in World War I. He also had a chronic cough producing half a cup of white, frothy sputum per day, and when seen could walk 600 yards or climb one flight of stairs at his own speed. Physical and radiographic signs were typical of emphysema, and included slight cyanosis, bilateral inguinal herniae, expiratory rhonchi, and basal rales, with some "honeycombing" of the hilar regions in postero-anterior films. Physiological tests (Table II) confirmed the diagnosis.

Subject $\mathbf{O}$. N. was an alert but physically rather weak woman of 84 . She complained of shortness of breath for several years, and a chronic cough producing half a cup of white sputum per day. When seen, she was only able to walk the short distance from the car to the laboratory, and had difficulty in climbing more than two or three stairs. Physical and radiographic signs were in keeping with emphysema. There was also marked kyphoscoliosis. Auscultation showed sonorous expiratory rhonchi at the apices, fine rales at the base of the left lung, and splitting of both first and second heart sounds in the pulmonary area. Postero-anterior radiographs showed also a patchy fibrosis of the right lower lobe of the lung. Physiological findings were typical of emphysema (Table II).
Considering first the patients with resting hyperventilation, in two the increase was mainly of tidal volume, and in the third of respiratory rate. In all, the diffusing capacity was much reduced, and the effective dead space much enlarged (in this connexion it should be emphasized that the prediction formula also takes account of the increased tidal volume). On the other hand, pulmonary blood flow was maintained at or above the expected level. The nitrogen-meter dead space was rather less than expected at this age, and probably reflects the asthmatic element of the illness.

The fourth subject (O.N.) had a breathing pattern suggestive of impending respiratory failure, with a shallow tidal volume, rapid respiratory rate, and limited breathing reserve. Perhaps on this account, there was no hyperventilation at rest. The consequences were a normal effective dead space, and a very low value for pulmonary flow. Total cardiac output was not measured, but in view of the impaired helium mixing, it seems probable that poor ventilation of perfused alveoli rather than a reduction of cardiac output was largely responsible. Similarly, resting hyperventilation was sufficient to maintain a normal effective flow in the other three subjects, despite poor gas distribution.

(3) Industrial Diseases.-Three patients were submitted for evaluation of employment disability. Two, with diagnoses of bronchiectasis and pneumoconiosis, were relatively fit ; the other, shown by physiological tests to have an alveolarcapillary block, was severely disabled. This again may be related to the fact that moderate hyperventilation permits a considerable degree of compensation for inequalities of ventilation and perfusion, but is less able to correct for a poor diffusing capacity.

Bronchiectasis and Bronchitis. - A man aged 50 을 (J. E.) had worked with a demolition team for $20 \mathrm{~N}$ years. For three years he had noticed a chronic $ᄋ$ cough and intermittent episodes of producing a large $N$ amount of sputum lasting several weeks and $N$ recurring every few months. Bronchiectasis was $\omega$ diagnosed on (i) a history of coughing up some blood on one occasion, and (ii) a bronchogram. It $\leftrightarrow$ was suggested that dust exposure might have $\mathbb{\varnothing}$ contributed to the development of his condition. He $\stackrel{?}{+}$ was also a heavy smoker (30 cigarettes daily). When 0 seen, he could climb four flights of stairs at his own $\bar{O}$

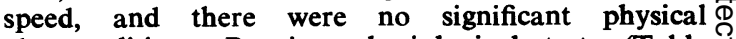
abnormalities. Routine physiological tests (Table $\underset{\mathbb{D}}{\mathbb{Q}}$ III) showed only a moderate reduction of static and $\varrho$ dynamic lung capacity.

Partitional respirometry showed a moderate $\varnothing$ increase of respiratory minute and tidal volume. 
TABLE III

ROUTINE TESTS OF PULMONARY FUNCTION IN THREE PATIENTS REFERRED FOR INDUSTRIAL DISEASE EVALUATION

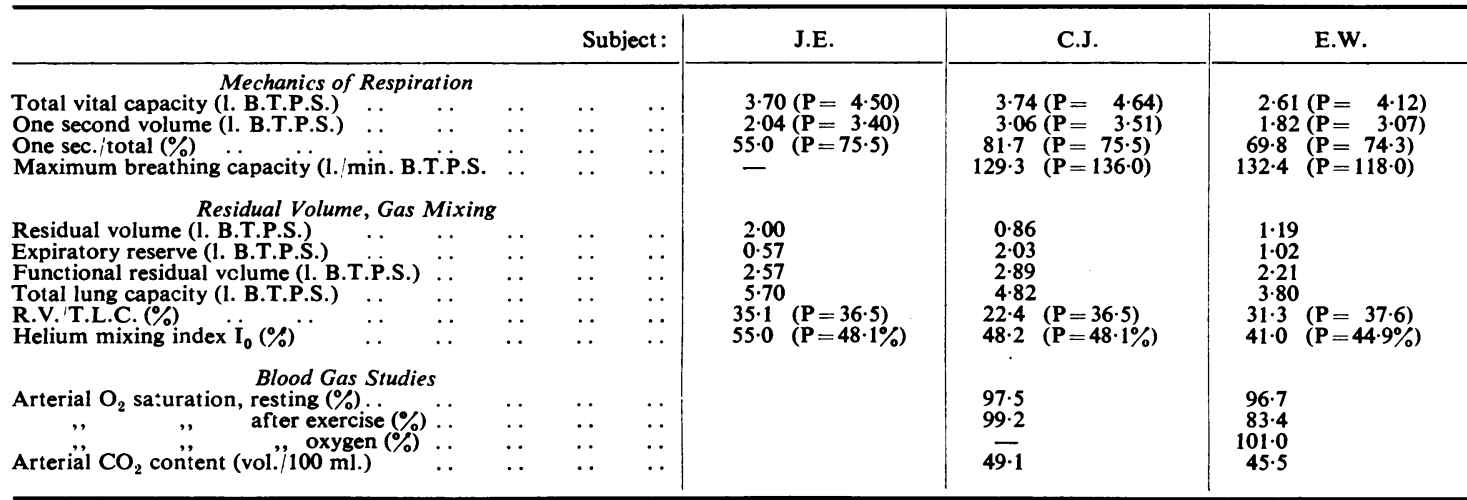

The effective diffusing capacity was well maintained, and there was a considerable increase of effective dead space. It is important to note that this was not revealed by the usual helium mixing test. The fact that the nitrogen-meter dead space was within normal limits suggests that bronchitis probably played a larger role than bronchiectasis in the production of his symptoms.

Early Pneumoconiosis.-A coloured man aged 49 (C. J.) had worked in a foundry for 25 years, spending much of this time on chipping and grinding work. He complained of difficulty in sleeping and recurrent attacks of "influenza," numbering a dozen in the preceding year, each lasting three to four days, and accompanied by chills, fever, sweating, cough, and production of up to a tablespoonful of greenish sputum streaked with blood. When seen, he could climb four flight of stairs without pause, and there was no significant physical abnormality. However, radiography showed mottling of the lung fields, sparse peripherally but sufficient partially to obscure the vascular markings in the hilar region. Routine tests (Table III) showed an impairment of respiratory mechanics affecting the static more than the dynamic capacity.

Partitional respirometry showed little abnormality. There was a rapid respiratory rate and increased minute volume, and effective pulmonary blood flow was above the expected level. The increase in respiration and cardiac output seemed a reflection of emotional or systemic disturbance rather than the pneumoconiosis, and the presence of some systemic ailment was suggested by the finding of a total white blood cell count of 3,200 cells/c.mm., with only $31 \%$ polymorphs.

Alveolar-capillary Block.-A man aged 54 (E.W.) had a varied industrial history, including two periods totalling 12 years in a sawmill, and nine years in the buffing department of a factory making car accessories. He claimed that he had been fit until three months previously, when he developed an attack of
" influenza" with fever, a dry, hacking cough, and dyspnoea on walking. The acute illness resolved after treatment by penicillin injections, but he remained short of breath, so that the climbing of two flights of stairs produced severe dyspnoea. Physical examination showed moderate cyanosis and early clubbing of the fingers, but no other significant abnormalities. Physiological tests (Table III) showed a gross reduction of static capacity with normal air movement and little impairment of helium mixing. The arterial oxygen saturation was greatly reduced by exercise.

At partitional respirometry, there was a rapid respiratory rate and an increased respiratory minute volume, but the most striking feature was a gross reduction of effective diffusing capacity. The increased ventilation and cardiac output probably represent an attempt to compensate for the poor diffusing capacity, although the increase of nitrogenmeter dead space suggests the process causing loss of diffusing capacity may also be causing some distension of the airways. This view is supported by the normal maximum breathing capacity despite the reduced vital capacity. The precise aetiology of the disease process has yet to be determined in this interesting case.

(4) Old AGE.-Four elderly patients with emphysema have already been described (Section 1). It is finally of some interest to consider gas uptake in elderly patients with an otherwise normal respiratory system. Six in the age range 60-70 years were studied. The findings at partitional respirometry were abnormal in two (G. B. and F. A.).

Subject G. B. was a woman of 70 with no symptoms and no known abnormality other than a cardiac irregularity, believed to be arteriosclerotic in origin. Routine tests showed some limitation of total vital capacity (2.4 1. B.T.P.S.) and one second volume (1.5 1. B.T.P.S.), but residual volume (1.74 1., $40.4 \%$ 
of total lung capacity) and helium mixing index $I_{0}=$ $37.5 \%$ ) were not greatly abnormal. Subject F. A. was a man of 66 , with no symptoms and no abnormality at physical examination. Routine function tests were not carried out in his case. It is perhaps significant that both G. B. and F. A. were retired, while the other four subjects were all still engaged in active work around the laboratory.

Considering first the four more normal subjects (L. B., A. K., R. M., and E. L.), effective diffusing capacity and pulmonary flow were close to the predicted values, but effective dead space and nitrogen-meter dead space were both moderately increased. Subjects F. A. and G. B. showed also a considerable reduction of diffusing capacity. In F.A., effective pulmonary flow was less than predicted, suggesting some perfusion inefficiency, while in G. B. a normal resting flow was maintained at the expense of considerable hyperventilation.

\section{Discussion}

A previous report from this laboratory (Shephard, 1958) has shown that in normal healthy subjects partitional respirometry is a useful physiological tool yielding numerical values for gas distribution (effective dead space), diffusing capacity, and pulmonary blood flow that are both reasonable and also in fair agreement with expected figures, where these are known. The present paper shows that despite several theoretical problems, the method also gives valuable information not readily obtained by other means in a variety of cardiac and pulmonary diseases.

Perhaps the theoretical difficulties should be discussed first. In a homogeneously ventilated and homogeneously perfused system, results are independent of the air/liquid partition coefficient of acetylene and ether. However, as the system becomes non-homogeneous, numerical values for effective dead space and pulmonary perfusion become increasingly dependent on the physical characteristics of the gases used in the test. Gases with a high partition coefficient $(\lambda)$ divide a given ventilation/perfusion inequality into a small dead space and a large perfusion component. With a smaller $\lambda$, dead space is increased, and perfusion inefficiency decreased. On theoretical grounds, it seems desirable to use gases with coefficients that bracket the values for $\mathrm{CO}_{2}(\lambda \cong 8.8)$ and $\mathrm{O}_{2}$ $(\lambda \cong 1.3)$, and acetylene $(\lambda=0.75)$ and ether $(\lambda=15.0)$ are suitable in this regard. The validity of an attempt at precise delineation of ventilation and perfusion components of the inequality may indeed be questioned, since it seems that by an increase of ventilation a subject can often transform an inefficiency of perfusion into an inefficiency of ventilation. Partitional respirometry gives a quantitative index of inequalities in the ventilation/perfusion ratio, and the significance to be attached to the relative numerical values for effective dead space and perfusion inefficiency may not be of great importance.

A more serious problem is created by the correction term used in calculating the effective diffusing capacity. This is based on the value obtained for effective dead space. The use of this term is probably preferable to attempts at end-tidal sampling, but the correction for overventilated and under-perfused areas may be excessive, since there is no guarantee that an increase of perfusion in these parts of the lung would increase diffusing capacity. Further, in patients where the inequality is partitioned to yield a large component of ineffective perfusion, there is no ready method of correcting the diffusing capacity short of a simultaneous measurement of cardiac output. Despite these theoretical disadvantages, the worth of partitional respirometry would seem proven in the majority of the cases studied here.

In congenital heart disease, normal values for effective dead space indicate an equality of ventilation/perfusion ratios, and in this relatively homogeneous system pulmonary blood flow is measured by partitional respirometry with sufficient accuracy to make it of use as a screening procedure. Indeed, where the pulmonary capillary saturation is unknown, it may even rival the Fick principle. Concomitant measurements of diffusing capacity may also have considerable prognostic significance. Normally, the large pulmonary flow of a left-to-right shunt should produce an increase of diffusing capacity, and where diffusing capacity is reduced, changes in the pulmonary vascular bed associated with progressive pulmonary hypertension (Shephard, 1954) may be suspected. Cardiac catheterization can sometimes provide a clue to such a change, $N$ but the evidence is less certain, since a small N right-to-left shunt could also be responsible, and the administration of oxygen during catheterization (Mounsey, Ritzmann, Silverstone, Briscoe, and McLemore, 1952 ; Brotmacher, 1957) does not always distinguish this possibility.

The effect of emphysema on gas uptake is a source of current controversy. Steady-state methods (Bates, Knott, and Christie, 1956; Shephard, Carey, and Phair, 1958) have shown a consistent decrease of carbon monoxide uptake in emphysema, and considerable diffusion 
impairment has also been demonstrated by measuring the maximal diffusing capacity for oxygen (Shepard, Cohn, Cohen, Armstrong, Carroll, Donoso, and Riley, 1955). Advocates of the breath-holding method for $\mathrm{D}_{\text {co }}$, notably Marshall (1958), have maintained that this is largely a reflection of poor gas distribution, although it should perhaps be pointed out that Marshall's own data for 11 cases of emphysema show a diffusing capacity that is uniformly less than predicted values (Ogilvie, Forster, Blakemore, and Morton, 1957), despite the much larger lung volume $($ mean $=6.94$ 1.) during the tests. Partitional respirometry provides further evidence that diffusing capacity is reduced independently of gas distribution effects. In the three well-compensated cases studied here, pulmonary blood flow was close to the predicted value. Some perfusion inefficiency could be concealed by an abnormally high resting pulmonary flow, but the low cardio-thoracic ratios (42, 43, and 44) make this unlikely. Although emphysema is traditionally regarded as a cause of high-output failure (McMichael and SharpeySchafer, 1944), the mean cardiac index gathered from some 20 reported cardiac catheterizations (Hickam and Cargill, 1948 ; Riley, Himmelstein, Motley, Weiner, and Cournand, 1948 ; Mounsey et al., 1952) is $4.01 . / \mathrm{m}^{2} / \mathrm{min}$., suggesting that a large increase of pulmonary flow would be an unusual finding. It seems more reasonable to assume that a good perfusion efficiency is normally achieved at the expense of increased ventilation and ventilatory inefficiency. Since partitional respirometry makes allowance for inefficiency of ventilation, and diffusing capacity is still very low, it may be presumed that this represents a genuine effect of emphysema on the diffusing surface, presumably through a reduction in the capillary bed.

The onset of right heart failure has been considered a serious turning point in the natural history of emphysema, but the present study suggests the possibility that this ominous development is preceded by a respiratory change. A stage in the disease process can be visualized where increase in the mechanical work of breathing and decrease of breathing reserve make it difficult for the patient to hyperventilate sufficiently to compensate for the poor gas distribution. Effective pulmonary flow is reduced, and a sequence of anoxia and pulmonary vasoconstriction leads to cardiac embarrassment and ultimate failure. This pattern rather than frank anatomical destruction of a critical proportion of the pulmonary vascular bed seems in keeping with the known reversal of cardiac failure following therapeutic measures to improve ventilation. Subject $\mathbf{O}$. N. appeared to have reached this stage, and in her case the low diffusing capacity could be due in part to distribution effects, but the diffusing capacity is so small that again a genuine effect on the diffusing surface must also be postulated.

In the three cases of industrial disease, the main value of partitional respirometry was in its decisive separation of bronchial disease (case of bronchitis and bronchiectasis with disturbed ventilation/perfusion relationships and normal diffusing capacity) from disease of the lung proper (case of alveolar-capillary block, with gross diffusion defect, and relatively normal ventilation/perfusion relationships). In such conditions, partitional respirometry is more searching than the conventional helium mixing test, which cannot detect inefficiencies of perfusion, and does not correct for areas which are poorly ventilated but also poorly perfused. It also has advantages over conventional measurements of diffusing capacity. The breath-holding method indicates a low value in $80 \%$ of cases of alveolar-capillary block (Marks, Cugell, Cadigan, and Gaensler, 1957), but an increase of chest volume or pulmonary flow can give a false normal answer, while the steady-state method can give a false low reading due to distribution effects. In the case with early pneumoconiosis, partitional respirometry was not particularly helpful. Hatch and Cook (1955) reported a decrease of both ether and carbon monoxide uptake, but their subjects were old men who had worked in coalmines for many years and were sufficiently disabled to be incapable of active work. The present findings support the verdict of Gilson and Hugh-Jones (1955) that tests of respiratory mechanics have a greater discriminatory capacity in early pneumoconiosis.

The effect of age upon diffusing capacity is another source of conflict between advocates of breath-holding and steady-state methods. Ogilvie et al. (1957) found no correlation between breathholding $\mathrm{D}_{\mathrm{co}}$ and age, and suggested technical reasons for the decrease of maximal diffusing capacity reported by Cohn, Carroll, Armstrong, Shepard, and Riley (1954). Shephard et al. (1958) observed a decrease of resting carbon monoxide uptake with age, but this could also be interpreted as a distribution effect. Partitional respirometry shows an unequivocal decline of diffusing capacity with age (Shephard, 1958), and it is of some interest that four of the six subjects now studied in the range 60-70 years do not depart from predicted values based on the 
trend throughout adult life. The remaining two subjects have a diffusing capacity as low as seen in emphysema, and it must be presumed that the natural ageing process has been accelerated in their case. The presence of a causal relationship between this finding and retirement is an interesting speculation. All six subjects have an effective dead space that exceeds the predicted value, showing that defects of gas distribution are accelerated in the seventh decade.

In summary, the equipment needed for partitional respirometry is as yet expensive, and will probably remain limited to rather specialized research centres. However, the method seems applicable not only in normal subjects but in most disease states, and the one circumstance theoretically limiting interpretation of the data (an inefficiency of pulmonary perfusion) does not seem very common. Further, no other test available at this time will yield as much information about the gas uptake process with so little inconvenience to both patient and investigator.

\section{SUMMARY}

The technique of partitional respirometry has been evaluated in a variety of disease states, and found to yield useful information concerning ventilation/perfusion relationships and effective diffusing capacity with minimal inconvenience to patient and investigator.

In congenital heart disease it has been possible to determine pulmonary blood flow and show a decrease of diffusing capacity associated with pulmonary hypertension. A decrease of diffusing capacity has been demonstrated in emphysema, and it has been noted that well-compensated patients maintain a normal effective pulmonary flow at the expense of hyperventilation and inefficiency of ventilation. Loss of resting hyperventilation is suggested as a critical development in this condition. In evaluation of industrial disease the method showed a clear separation of bronchial and alveolar disease, and should be particularly valuable in the alveolar-capillary block syndrome.

Ageing is associated with a progressive decrease of both diffusing capacity and ventilatory efficiency. In some individuals deterioration of diffusing capacity is accelerated in the seventh decade, and all show a more rapid decrease of ventilatory efficiency.

This work was supported in part by a research grant from the U.S. Public Health Service, National Institutes of Health. It is one of a series of $\vec{A}$ continuing interrelated investigations having as their principal objective the measuring of the pulmonary reactions of man to low-level air pollution. Dr. ज John J. Phair, Professor of Preventive Medicine, is principal investigator for the grant. Four of the cases described herein were under the care of Dr. Frank $\vec{c}$ Princi, and two were under the care of Drs. S. Kaplan and J. Braunstein. I am indebted to them for $\mathbb{D}$ making available details of clinical and radiological $\vec{\theta}$ examinations, and data pertaining to cardiac catheterization.

Bartlett, R. G. $12,247$.

Bates, D. V., and Christie, R. V. (1950). Clin. Sci., 9, 17. Knott, J. M. S., and Christie, R. V. (1956). Quart. J. Med.

25, 137.
Brotmacher, L. (1957). Guy's Hosp. Rep., 106, 29.

Cohn, J. E., Carroll, D G., Armstrong, B. W., Shepard, R. H., and. Riley, R. L. (1954). U.S. Air Force Proj., 20-1201-0014, Rep. No. 4.

Gilson, J. C., and Hugh-Jones. P. (1955). Spec. Rep. Ser. med. Res. Coun. (Lond.), No. 290

Hatch, T., and Cook, K. M. (1955). A.M.A. Arch. industr. Hlth, 11,142 .

Hickam, J. B., and Cargill, W. H. (1948). J. clin. Invest., 27, 10.

Marks, A., Cugell, D. W., Cadigan, J. B., and Gaensler, E. A. (1957). Amer. J. Med., 22, 51.

Marshall, R. (1958). J. clin. Invest., 37, 394

McMichael, J., and Sharpey-Schafer, E. P. (1944). Quart. J. Med., \& $13,123$.

Mounsey, J. P. D., Ritzmann, L. W., Silverstone, N. J., Briscoe, $\bar{O}$ W. A., and McLemore, G. A. (1952). Brit. Heart J., 14, 153.

Ogilvie, C. M., Forster, R. E., Blakemore, W. S., and Morton, J. W. (1957). J. clin. Invest., 36, 1.

Riley, R. L., Himmelstein, A., Motley, H. L., Weiner, H. M., and Cournand, A. (1948). Amer. J. Physiol., 152, 372.

Shepard, R. H., Cohn, J. E., Cohen, G., Armstrong, B. W., Carroll, D. G.,Donoso, H., and Riley, R. L.(1955). Amer. Rev. Tuberc., 71, 249.

Shephard, R. J. (1954), Brit. Heart J., 16, 361. (1955). Ibid., 17, 153

(1956a) J. Physiol. (Lond), 134, 630

(1956b). Thorax 11 223.

(1956b). Thorax, 11, 223.

(1957). J. Physiol. (Lond.), 135, 98.

Carey, G. C. R., and Phair, J. J. (1958). Ibid., 12, 79. 